\title{
To Increasing the Capacity of DWDM System using Add/drop Multiplexers with Splitters and Couplers
}

\author{
Daleep Singh Sekhon* and Harmandar Kaur \\ Deptt. of ECE, GNDU Regional Campus, Sathiala, Punjab, India \\ Deptt. of ECE, GNDU Regional Campus, Jalandhar, Punjab, India \\ *dssekhon24@gmail.com
}

\begin{abstract}
In this paper, we investigate the DWDM system using Add/drop multiplexers with splitters and couplers for increasing the capacity of system. In this DWDM system 2 channel at transmitter section each having data rate 10Gbps (i.e. 20Gbps) are transformed into 64 channel at receiver section each having data rate 10Gbps (i.e.640Gbps) by using Add/drop multiplexer which drops the optical signals of some frequency which are split up by different splitters and those signals are coupled by the various couplers for enhancing the capacity of system. The couplers coupled the signals coming from de-multiplexers and splitters and passed the signals into different receivers. The performance of system is defined on the basis of BER, eye height and quality factor. The system generates good and viable result and performed better up to $420 \mathrm{~km}$ optical fiber link length.
\end{abstract}

Keywords: DWDM; Add/drop Mux; Splitters; Couplers; BER; Q-factor

\section{Introduction}

The DWDM technology has been deployed for meet the growing demands of bandwidth that multiplies the capacity of single fiber. The DWDM optical network using with OADM (optical add/drop multiplexers) is moving the telecommunication industry closer to the development of future generation high speed optical networks. DWDM system with OADM makes network flexible to accommodate the revenue-generating traffic and reduces cost of network by using less bandwidth. The using of optical cross couplers, optical splitters with optical add/drop multiplexers in the DWDM optical communication system provides the infrastructure capable of meeting the high speed telecommunications network. In now days, in optical communication system the DWDM system is used as high speed data networks and also data rate can be converted from Gbps to Tbps using OADM with splitters and couplers. In literature review, the performances of 10Gbps optical communication network with different topologies that is bus, ring, star and tree in the presence of optimized semiconductor optical amplifier and concluded that for all topologies number of user supported by network depends upon number of semiconductor amplifier and couplers present in the network [1]. Summarizing of basic optical network approaches and discussing the WDM deployment strategies and outline the current development and research trends on WDM optical networks for achieving the speed of system up to 1Tbps [2]. Designing of OADM based DWDM ring network for six nodes and using 30 wavelengths in unidirectional non linear single mode fibre by using 10Gbps data rates of BPSK modulation format and system performance is described on the basis of Q-factor, BER and the eye diagram of metropolitan ring network [3]. Using of OADM in DWDM system for high transmission data rates for productions of next generation optical networks [4]. Upgrading the data rate of DWDM system using

Received (July 5, 2017), Review Result (September 22, 2017), Accepted (October 12, 2017) 
$\mathrm{ADD} /$ drop multiplexers along with couplers and the system data is converted from $20 \mathrm{Gbps}$ to $160 \mathrm{Gbps}$ at $180 \mathrm{~km}$ link length [5]. Analysis the performances of Wavelength Division multiplexing optical networks with two novels Add/drop multiplexers along using with self-healing techniques for making network reliable [6]. Designing of selfhealing access ring networks in DWDM system with cost saving, cross talk free with using bi-directional optical Add/drop multiplexers (OADM) in single fibre and finds that this architecture simplifies the hub complexity and also by using this networking model low cost components are employed at each node [7]. Studying of add/drop applications in fibre ring networks by using reconfigurable Add/drop multiplexers in a re-circulating loops by applying 7 cascaded Add/drop nodes at every $150 \mathrm{~km}$ along the transmission path [8]. Design of 64 channels DWDM system with channel having a data rate of 20Gbps using Optimized modulation format to achieve system capacity up to $1.28 \mathrm{Tbps}$. It was found that system having ultra high capacity of $1.28 \mathrm{Tbps}$ is expected to be more technically viable with use of only Optimized modulation format and this system is highly useful for high speed data processing computer networks [9]. To Investigate the principle of adding or dropping of channel by using Optical Add/drop multiplexers for an Orthogonal Frequency Division Multiplexing (OFDM) system and Integrated DWDM (IDWDM) systems [10].

\section{System Design}

To investigate the performance of DWDM system using add/drop multiplexers with couplers and splitters to increasing the capacity of system. A simulation model of transforming the capacity of 20Gbps DWDM system to 640Gbps system is designed. It consists of Transmitter section, Wavelength adding/dropping and coupling section and Receiver section. The system performance is defined in terms of BER, Q-factor and eye height at $340 \mathrm{~km}$ and $420 \mathrm{~km}$ by using DCF of length $14.656 \mathrm{~km}$ where system generates good and favourable results. Block diagram of system set up as shown in Figure 1. In this diagram, Transmitter section transmit two different optical channel signals which is multiplexed by 2:1 multiplexer and passed through optical fiber then followed by optical amplifier and then further through Drop-Mux section which drops the different wavelength channels with $0.8 \mathrm{~nm}$ equal channel spacing and also same wavelength channels which are dropped, added by using optical transmitter at Add-Mux section. Optical signal from add/drop section is passed into the 1:2 de-multiplexer which demultiplexed the signal. From Drop multiplexer section, dropped wavelength signal is further split up by different splitters present in splitter section from where signal is coupled to coupler section. Coupler section couples the optical signals from 1:2 demultiplexer and splitter section and passed the signal to receiver section for demodulating the signal into original form.

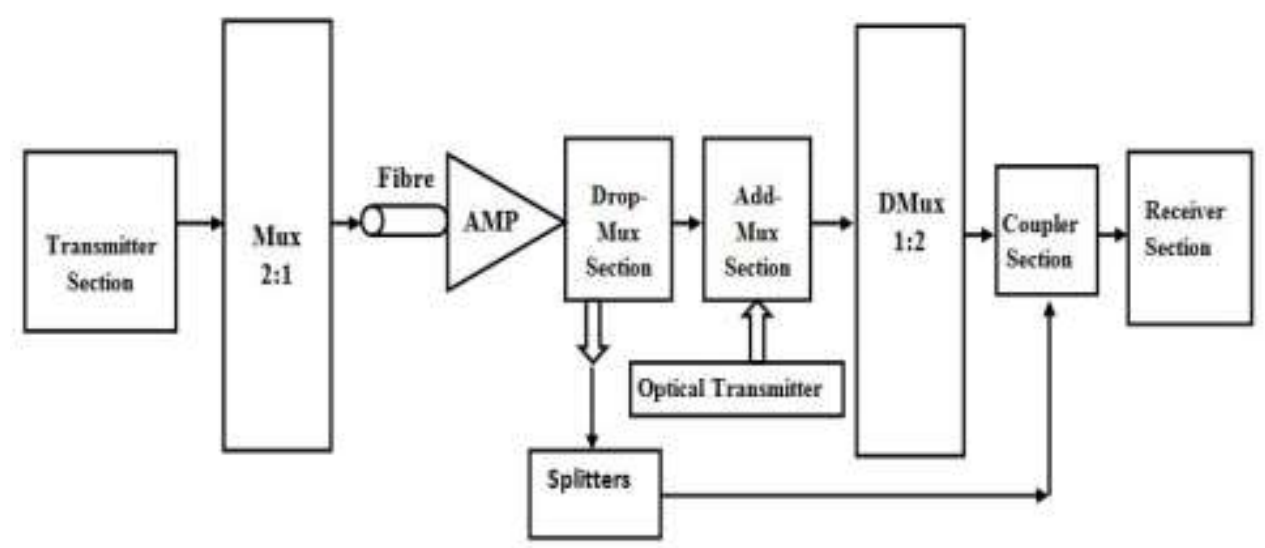

Figure 1. Block Diagram of System Set Up 


\section{Table 1. DWDM System Set Up Parameters using Add/Drop Multiplexers with Splitters and Couplers}

\begin{tabular}{|l|l|}
\hline System parameters & Values \\
\hline Number of transmitting channel & 2 \\
\hline Each channel data rate & $10 \mathrm{Gbps}$ \\
\hline Channels Frequency & $193.1 \mathrm{THz}$ and 193.4THZ \\
\hline Channel Spacing & $0.8 \mathrm{~nm}$ \\
\hline Attenuation & $0.2 \mathrm{~dB} / \mathrm{km}$ \\
\hline Dispersion of SMF & $16.75 \mathrm{ps} / \mathrm{nm} / \mathrm{km}$ \\
\hline User supported in system & 64 \\
\hline Link length & $340,420 \mathrm{~km}$ \\
\hline DCF length & 14.656 \\
\hline Add/Drop multiplexer frequencies & $193.2 \mathrm{THz}$ and 193.3THz \\
\hline
\end{tabular}

\subsection{Transmitter Section}

Transmitter section consists of 2 transmitter channel where each channels operating at its own frequency that is $193.1 \mathrm{THz}$ and $193.4 \mathrm{THz}$ respectively. The data rate of individual channel is $10 \mathrm{Gbps}$ and therefore total data rate at transmitting section is 20Gbps. Each transmitter channel include a Data source that is pseudo random sequence, RZ coder for coding the signal into Non return to zero format, Continuous wave laser source as an optical source which provides optical signal of particular frequency which modulates the electrical signal in the Modulator (Match zehnder) to convert electrical signal into optical signal. Then these two optical signals are multiplexed by 2:1 multiplexer then transmitted into optical fiber and then through Add-drop multiplexer which add or drop the frequencies with equal channel spacing of $0.8 \mathrm{~nm}$ on demand. The transmitter section diagram for system set up as shown in Figure 2.

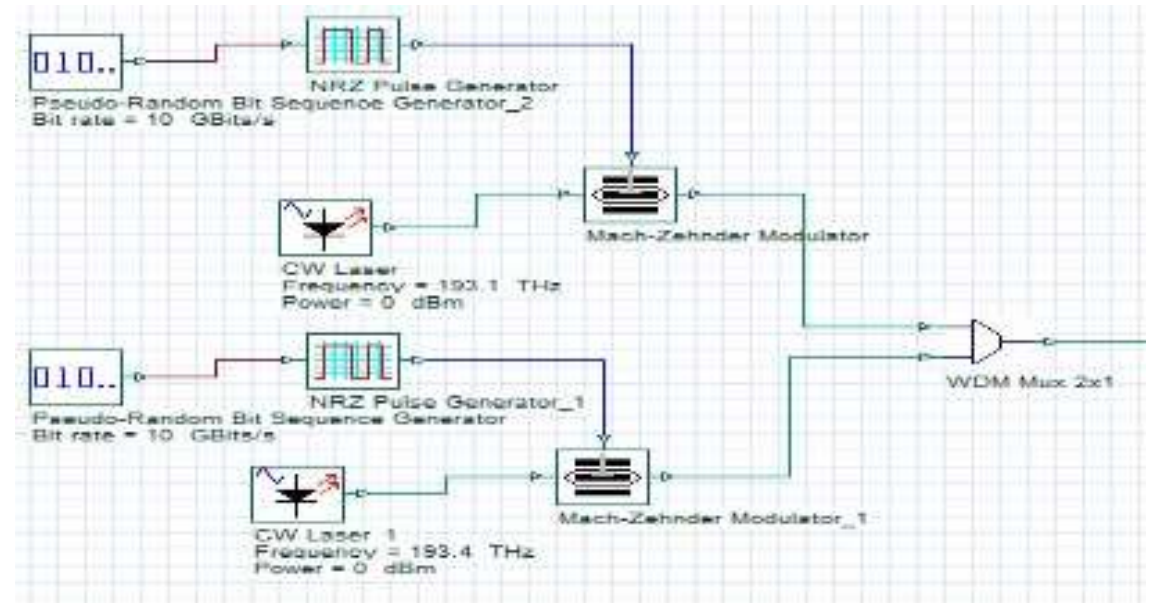

Figure 2. Transmitter Section Diagram of System Set Up

\subsection{Wavelength Add/drop and Coupling Section Design}

In DWDM networks for increasing capacity some traffic at intermediate points is dropped or added on demand by using add/drop multiplexers. Use of splitters with couplers increases capacity but also cost efficient system because lesser number of Add/drop multiplexer is required and this makes the system band efficient. In this section, two Add/drop multiplexers are used which add or drop the frequency channels of $193.2 \mathrm{THz}$ and $193.3 \mathrm{THz}$ respectively with equal channel spacing that is $0.8 \mathrm{~nm}$. The dropped signal by Add/drop multiplexer is passed through splitters (that is 1:31 splitter) 
which splits the signal into 1:31. The role of the splitters is same as de multiplexers to split the optical signal but de-multiplexers splits the signal into different frequencies as compared to splitters which splits the signal with same frequency. In this section two splitters are used to splitting $193.2 \mathrm{THz}$ and $193.3 \mathrm{THz}$ dropped frequency respectively, which is dropped by two drop multiplexers. Then those signals which are split up by different splitters are coupled by different couplers. Couplers used in this system have two input and two output ports. The first input port of coupler coupled the signal from 1:2 demultiplexers and second input port coupled the signal from splitters i.e. 62 optical signals which are split up by two 1:31 splitter are coupled by 62 couplers. The wavelength adding/dropping and coupling section set up diagram of system is shown in Figure 3. In this diagram, we give the example of using two 1:7 splitters and 14 couplers but actually in the designed system we used two 1:31 splitters and 62 couplers.

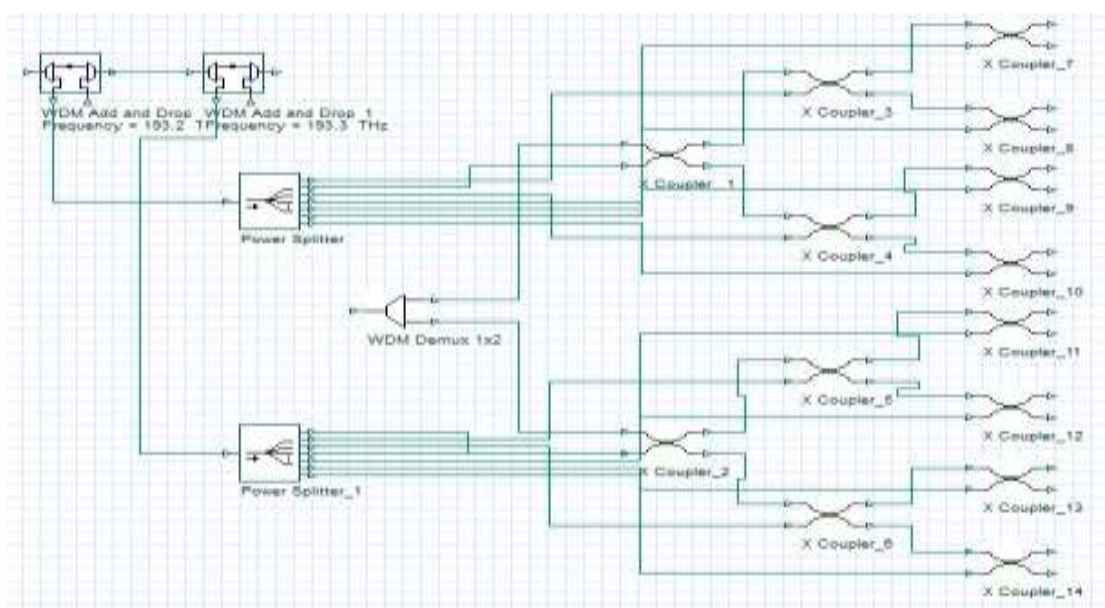
Figure 3. Wavelength Add/drop and Coupling Section Set Up Diagram
for System

\subsection{Receiver Section}

At the receiver section, the two optical signals from transmitter section of data rate each $10 \mathrm{Gbps}$ (i.e. 20Gbps) are transformed into 64 optical signals of data rate each $10 \mathrm{Gbps}$ (i.e. 640Gbps) using add/drop multiplexers with splitters and couplers. So, at receiver section there is a 64 receivers' block which couples the optical signal from 62 different couplers. Each receiver block consists of PIN photodiode as a photo detector which converts optical signal into electrical signal, followed by low pass rectangular filter which filtered the electrical signal, $3 \mathrm{R}$ regenerator which regenerates and reconstruct the signal into original form and eye diagram analyzer. Eye diagram analyzer provides the output of system on the basis of Q-factor, BER (bit error rate) and eye opening at particular $\mathrm{km}$ where system generates good and viable results. The receiver diagram for system set up as shown in Figure 4.

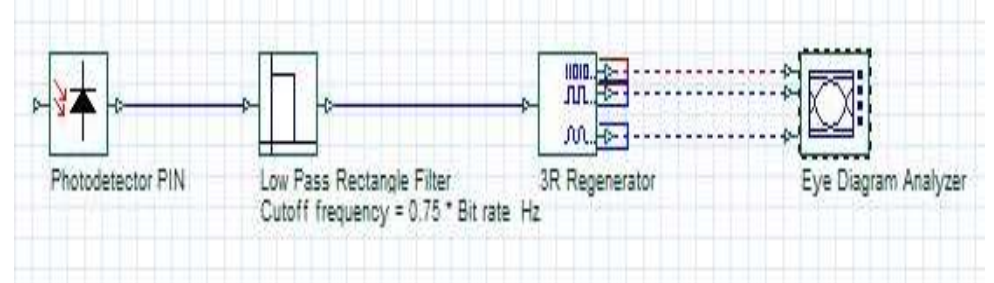

Figure 4. Receiver Set Up Diagram for System 


\section{Results and Discussion}

The DWDM system for increasing the capacity of system using Add/drop multiplexer with Splitters and Couplers for transforming the system from 20Gbps to 640Gbps is passed through optical fiber lengths of $340 \mathrm{~km}$ and $420 \mathrm{~km}$ respectively with DCF of length $14.656 \mathrm{~km}$ for compensating dispersion. In this system two transmitting channel each of $10 \mathrm{Gbps}$ data rate having frequencies $193.1 \mathrm{THz}$ and $193.4 \mathrm{THz}$ respectively is transmitted by two transmitter block which is multiplexed through 2:1 multiplexer and passed through the fiber then followed by add-drop multiplexers. The two Add/drop multiplexers dropped or added the frequency of $193.2 \mathrm{THz}$ and $193.3 \mathrm{THz}$ respectively and these two dropped frequencies are split up by two splitters into 1:31. These 62 optical signals from splitters are coupled into 62 couplers. Couplers one input port coupled the signal from de-multiplexers which de-multiplexed the signal coming from fiber and second port of coupler couples the signal from splitter and enhance the capacity of system. These signals are transformed into 64 receivers and each receivers receive $10 \mathrm{Gbps}$ data rate signal and transformed the bit rate of system from 20Gbps to 640Gbps. Eye diagram analyzer generates the output of system by analysis the eye diagram of different receivers in terms of Q-factor, BER and eye opening at $340 \mathrm{~km}$ and $420 \mathrm{~km}$ respectively where system generates good, acceptable results. But the system provides best results at $340 \mathrm{~km}$ where the values of Q-factor for all the receivers are approximately equal to $9 \mathrm{~dB}$ and also the system performance degrades beyond $420 \mathrm{~km}$. The signal strength received at receiver 1 of DWDM system using add/drop multiplexer with splitters and couplers at 340 and $420 \mathrm{~km}$ link length as shown in eye diagram in Figure 5.

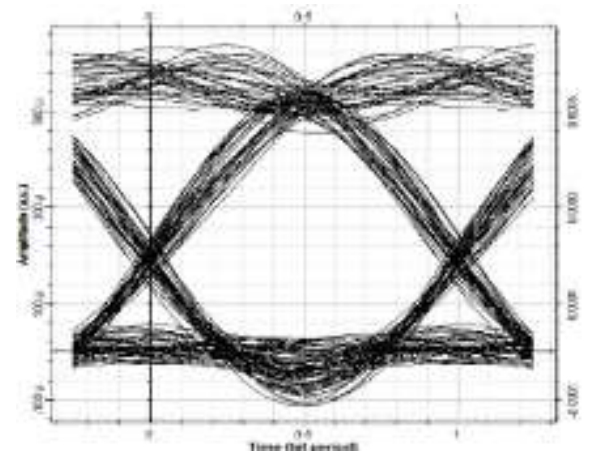

At $340 \mathrm{~km}$

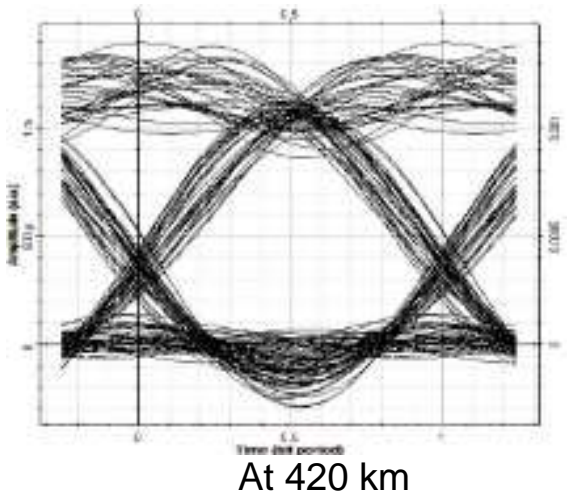

At $420 \mathrm{~km}$

Figure 5. Eye Diagram of Receiver 1 at $340 \mathrm{Km}$ and $420 \mathrm{Km}$ Link Length

The signal strength received at receiver 16 of DWDM system using add/drop multiplexer with splitters and couplers at 340 and $420 \mathrm{~km}$ link length as shown in eye diagram in Figure 6. 

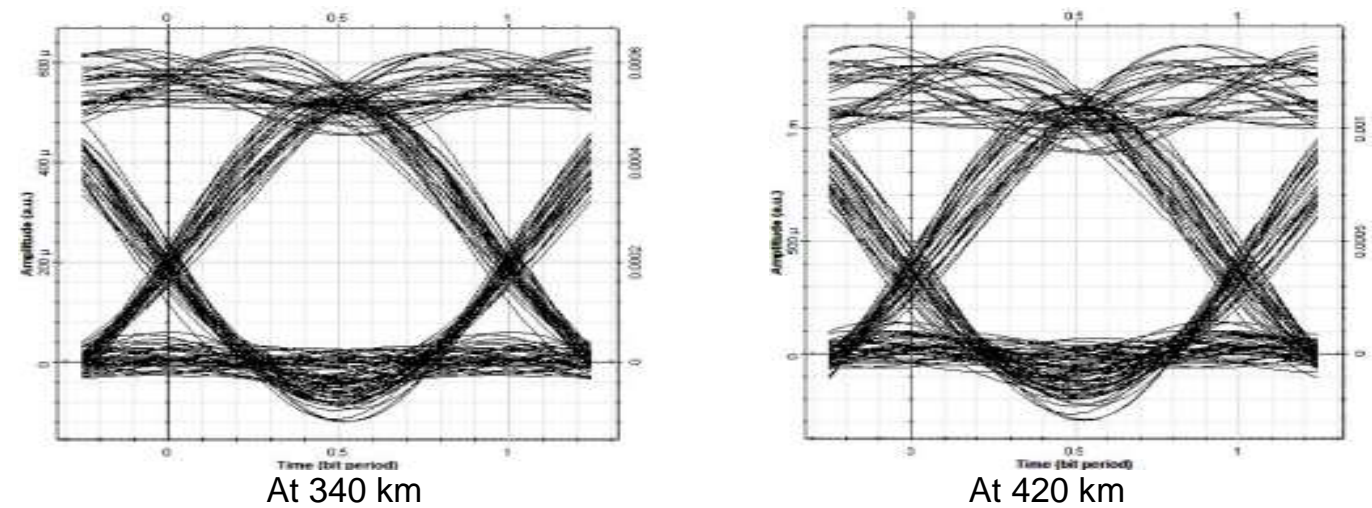

Figure 6. Eye Diagram of Receiver 16 at $340 \mathrm{Km}$ Aand $420 \mathrm{Km}$ Link Length

The signal strength received at receiver 32 of DWDM system using add/drop multiplexer with splitters and couplers at 340 and $420 \mathrm{~km}$ link length as shown in eye diagram in Figure 7.
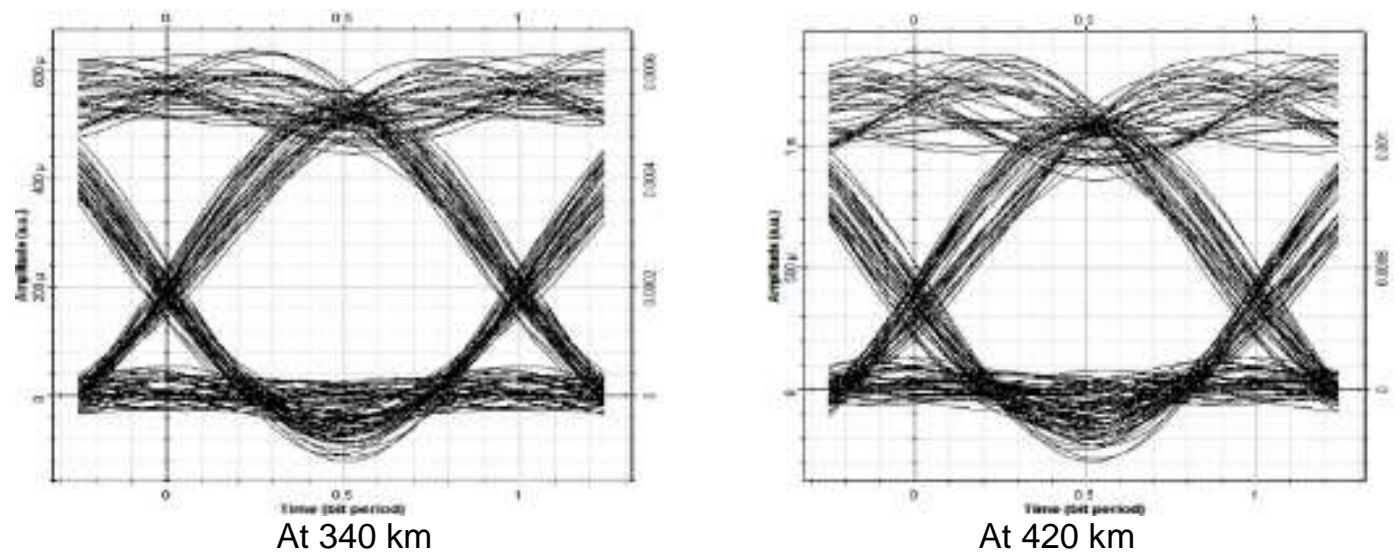

Figure 7. Eye Diagram of Receiver 32 at $340 \mathrm{Km}$ and $420 \mathrm{Km}$ Link Length

The signal strength received at receiver 48 of DWDM system using add/drop multiplexer with splitters and couplers at 340 and $420 \mathrm{~km}$ link length as shown in eye diagram in Figure 8.
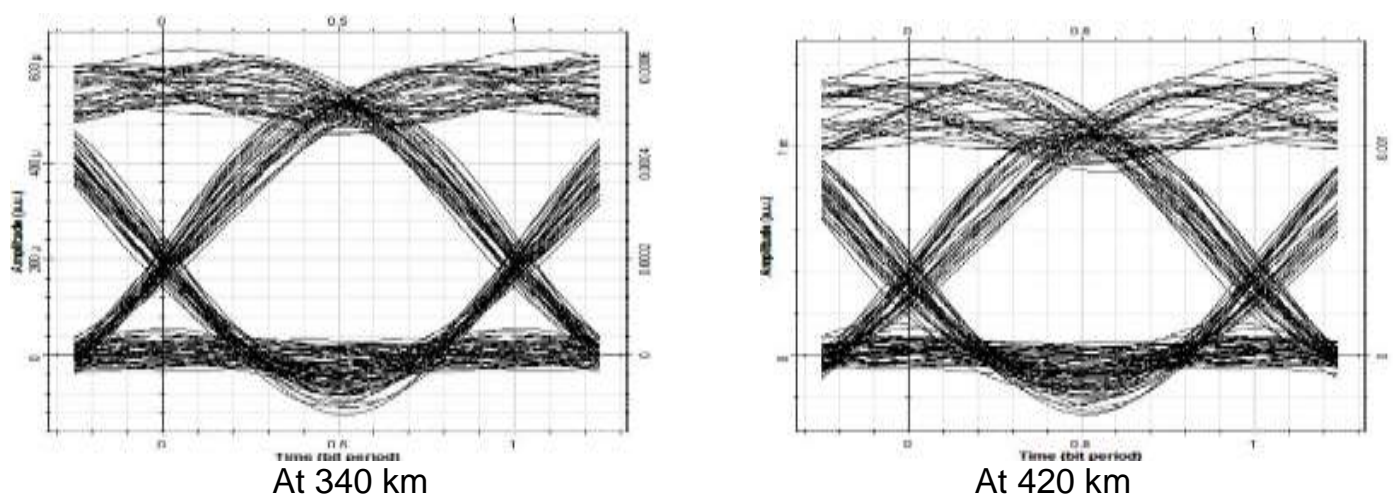

Figure 8. Eye Diagram of Receiver 48 at $340 \mathrm{Km}$ and $420 \mathrm{Km}$ Link Length

The signal strength received at receiver 64 of DWDM system using add/drop multiplexer with splitters and couplers at 340 and $420 \mathrm{~km}$ link length as shown in eye diagram in Figure 9. 

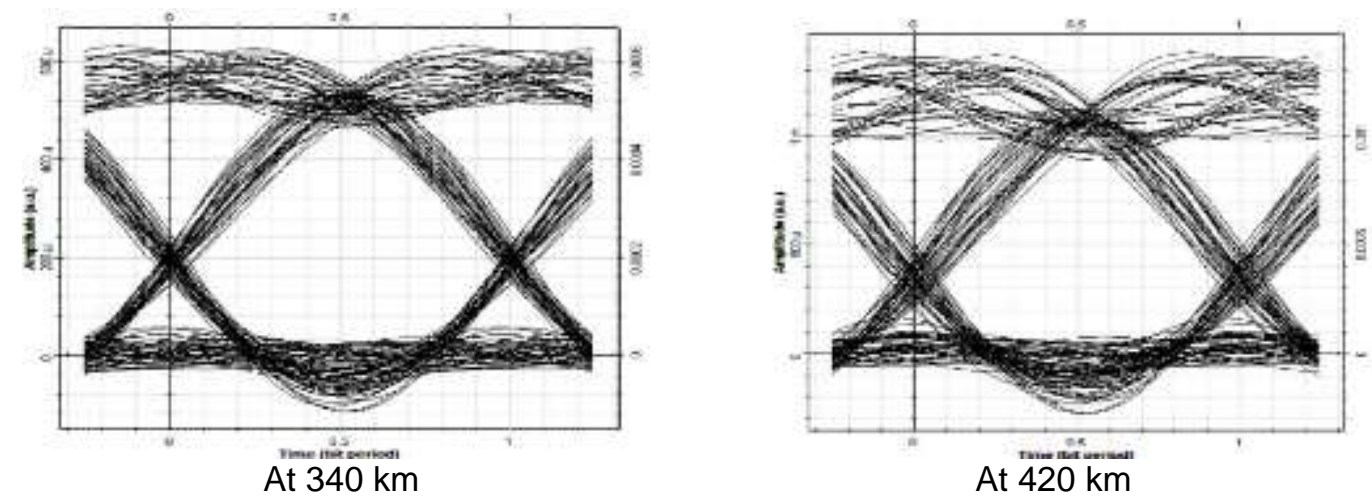

At $420 \mathrm{~km}$

Figure 9. Eye Diagram of Receiver 64 at $340 \mathrm{Km}$ and $420 \mathrm{Km}$ Link Length

The results of DWDM system using Add/drop Multiplexers with splitters and couplers at 340, 420 and $500 \mathrm{~km}$ link length are shown graphically by plotting graph of Q-factors and BER values for different receivers as shown in Figure 10. and Figure11. respectively. Graph shows that system generates good, acceptable results at $340 \mathrm{~km}$ and $420 \mathrm{~km}$, but the system provides best results at $340 \mathrm{~km}$ where the values of Q-factor for all the receivers are approximately equal to $9 \mathrm{~dB}$ and also the system performance degrades beyond $420 \mathrm{~km}$ (at $500 \mathrm{~km})$.

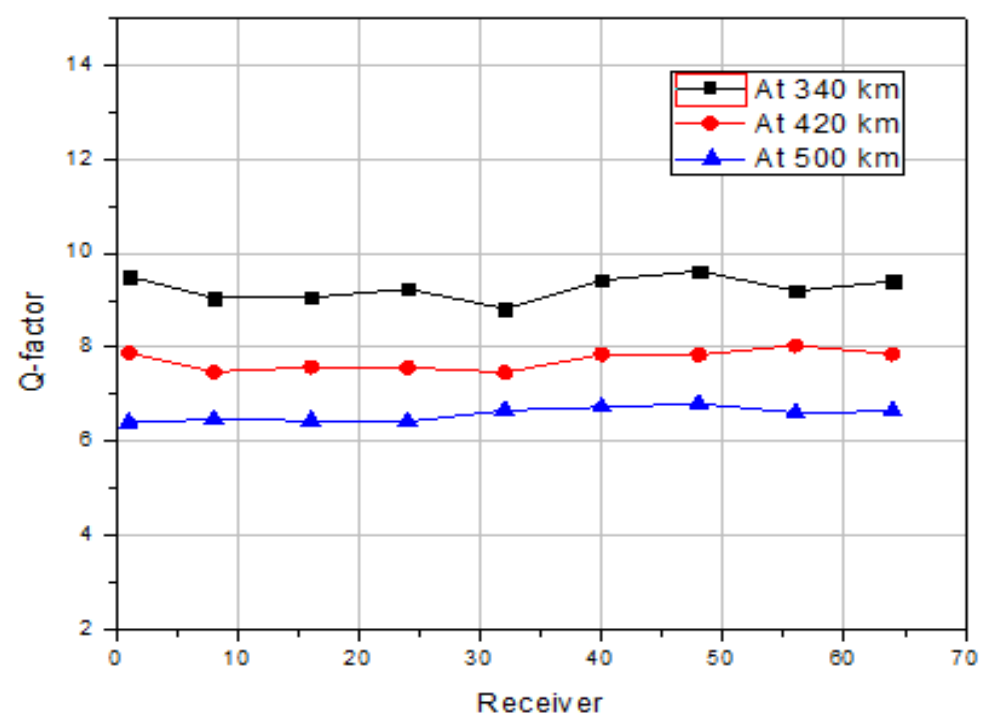

Figure 10. Comparison Graph of Q-Factor Values For Different Receiver Channels Of System At Different Km 


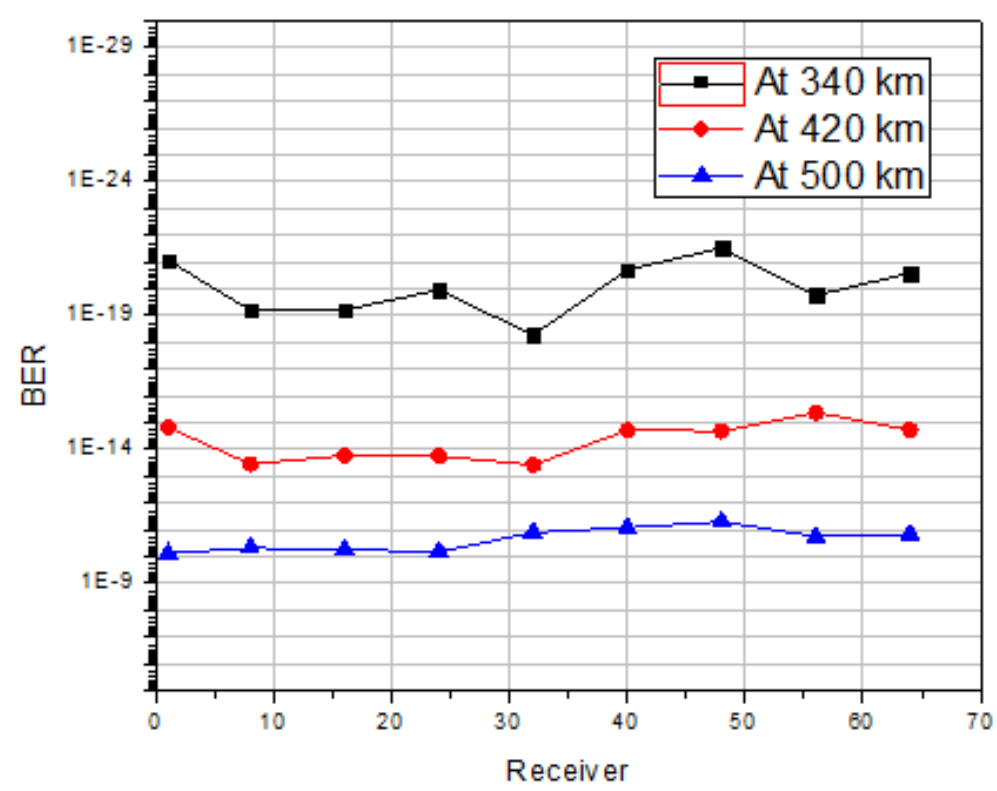

Figure 11. Comparison Graph of BER values for Different Receiver Channels Of System at Different Km

Table 2. The Values of Q-Factor of Different Receivers Channel of System at Different Km Link Length, Where System Provides Good and Acceptable Results

\begin{tabular}{|c|c|c|}
\hline Receivers & Q-factor at 340 km & Q-factor at $\mathbf{4 2 0} \mathbf{~ k m}$ \\
\hline Receiver 1 & 9.51 & 7.88 \\
\hline Receiver 8 & 9.05 & 7.48 \\
\hline Receiver 16 & 9.06 & 7.58 \\
\hline Receiver 24 & 9.24 & 7.57 \\
\hline Receiver 32 & 8.82 & 7.47 \\
\hline Receiver 40 & 9.43 & 7.85 \\
\hline Receiver 48 & 9.62 & 7.84 \\
\hline Receiver 56 & 9.20 & 8.04 \\
\hline Receiver 64 & 9.40 & 7.86 \\
\hline
\end{tabular}

Table 3. The Values of BER of Different Receivers Channel of System at Different Km Link Length, Where System Provides Good and Acceptable Results

\begin{tabular}{|c|c|c|}
\hline Receivers & BER at $\mathbf{3 4 0}$ km & BER at $\mathbf{4 2 0} \mathbf{~ k m}$ \\
\hline Receiver 1 & $8.89 \mathrm{e}^{-022}$ & $1.53 \mathrm{e}^{-015}$ \\
\hline Receiver 8 & $6.47 \mathrm{e}^{-020}$ & $3.59 \mathrm{e}^{-014}$ \\
\hline Receiver 16 & $6.18 \mathrm{e}^{-020}$ & $1.71 \mathrm{e}^{-014}$ \\
\hline Receiver 24 & $1.13 \mathrm{e}^{-020}$ & $1.77 \mathrm{e}^{-014}$ \\
\hline Receiver 32 & $5.35 \mathrm{e}^{-019}$ & $3.81 \mathrm{e}^{-014}$ \\
\hline Receiver 40 & $1.96 \mathrm{e}^{-021}$ & $1.93 \mathrm{e}^{-015}$ \\
\hline Receiver 48 & $3.02 \mathrm{e}^{-022}$ & $2.08 \mathrm{e}^{-015}$ \\
\hline Receiver 56 & $1.76 \mathrm{e}^{-020}$ & $4.22 \mathrm{e}^{-016}$ \\
\hline Receiver 64 & $2.60 \mathrm{e}^{-021}$ & $1.86 \mathrm{e}^{-015}$ \\
\hline
\end{tabular}




\section{Conclusion}

The performances of DWDM system using Add/drop multiplexer with Splitters and Couplers is evaluated on the basis of BER, Quality factor at different $\mathrm{km}$ link length. It is concluded that the system is upgraded from 20Gbps to $640 \mathrm{Gbps}$ and generates good, viable result at $340 \mathrm{~km}, 420 \mathrm{~km}$ link length but the system provides best result at $340 \mathrm{~km}$ and the system performance degrades beyond $420 \mathrm{~km}$ (at $500 \mathrm{~km}$ ). It is also concluded that by using Splitters with Couplers it increases the system capacity and also it makes the system cost effective because of use of lesser number of Add/drop multiplexers. By using lesser number of Add/drop multiplexer it makes the system band efficient. From this it is concluded that by using this optical networking model for short distance communication we can increase or upgrade the system capacity into Tbps (Terabits per second).

\section{Acknowledgments}

The author wishes to thanks Ms. Harmandar Kaur for the guidance provided in this research work.

\section{References}

[1] S. Singh, "Performance Comparison of Optical Network Topologies in the Presence of Optimized Semiconductor Optical Amplifiers", J. Opt. Commun. Netw. vol.1, no. 41, (2009), pp. 313-323.

[2] S. B. Anees, S. Khan and S. A. Ali, "Next Gen. Dense Wavelength Division Multiplexing", International Journal of Advanced Research in Computer Science and Software Enginnering, vol. 4, issue 6, (2014), pp. 1000-1008.

[3] J. Minhas. and R. Kochher, "Design and Performance Evaluation of DWDM based Metropolitan Ring networks", International Journal of Innovative Research in Computer and Communication Engineering vol. 3, issue 3, (2015), pp. 2142-2149.

[4] A. N. Z. Rashed, "Optical Add Drop Multiplexer (OADM) Based on Dense Wavelength Division Multiplexing Technology in Next Generation Optical Networks", Electrical and Electronic Engineering, vol. 1 no. 1, (2011), pp. 24-32.

[5] D. S. Sekhon, H. Kaur and J. Malhotra, "Upgrading a 20 Gbps DWDM system to 160 Gbps system using hybrid Add/drop multiplexers and couplers", Proceeding in International Conference on Computational Techniques in Information and Communication Technologies (ICCTICT), (2016), IEEE, pp. 544-550.

[6] P. C. Peng, C. H. Chang, H. H. Lu, Y. T. Lin, J. W. Sun and C. H. Jiang, "Novel optical add-drop multiplexer for wavelength-division-multiplexing networks", Optics Communications, vol. 285, (2012), pp. 3093-3099.

[7] C. H. Chang, T. C. Liang and C. Y. Huang, "DWDM self-healing access ring network with cost-saving, crosstalk-free and bidirectional OADM in single fiber", Optics Communications, vol. 282, (2009), pp. 4518-4523.

[8] M. F. Huang, J. Chen, K. M. Feng, T. Y. Lin, C. Y. Lai, C. C. Wei, S. Chi, Z. Zhu, Y. J. Chen, Y. C. Huang and S. J. Chang, "Add/drop applications in fiber ring networks based on a reconfigurable optical add/drop multiplexer in a recirculating loop", Optics Communications, vol. 267, (2006), pp. 113-117.

[9] B. Patnaik and P. K. Sahu, "Ultra high capacity 1.28 Tbps DWDM system design and simulation using optimized modulation format", Optik, vol. 124, (2013), pp. 1567-1573.

[10] K. S. Bhatia, "Simulative analysis of integrated DWDM and MIMO-OFDM system et al with OADM", Optik, vol. 124, (2013), pp.117-121.

[11] G. Kaur and M. S. Patterh, "Performance investigation of ring network toplogy in the presence of semiconductor", Optik International Journal for Light and Electron Optics, vol. 124, no. 22, (2013), pp. 5366-5368

[12] S Singh, "Investigation of wavelength division multiplexing ring network topology to enhance the system capacity", Optik, vol. 125, (2014), pp. 6527-6529. 
International Journal of Future Generation Communication and Networking Vol. 10, No. 12 (2017) 